\title{
UNIVERSITYOF
}

FORWARD

THINKING

WESTMINSTER用

WestminsterResearch

http://www.westminster.ac.uk/westminsterresearch

Human Rights Fact-Finding and the CIA's Rendition, Detention and Interrogation Programme: A Response to Cordell

Blakeley, R. and Raphael, S.

This is a copy of the accepted author manuscript of the following article: Blakeley, R. and Raphael, S. (2017) Human Rights Fact-Finding and the CIA's Rendition, Detention and Interrogation Programme: A Response to Cordell. International Area Studies Review, DOI:10.1177/2233865917735428. The final definitive version is available from the publisher Sage at:

https://dx.doi.org/10.1177/2233865917735428

(C) The Author(s) 2017

The WestminsterResearch online digital archive at the University of Westminster aims to make the research output of the University available to a wider audience. Copyright and Moral Rights remain with the authors and/or copyright owners.

Whilst further distribution of specific materials from within this archive is forbidden, you may freely distribute the URL of WestminsterResearch: ((http://westminsterresearch.wmin.ac.uk/).

In case of abuse or copyright appearing without permission e-mail repository@westminster.ac.uk 


\section{Human Rights Fact-Finding and the CIA's Rendition, Detention and Interrogation Programme: A Response to Cordell}

\section{Introduction}

In the wake of the 9/11 terror attacks on New York and Washington, the CIA developed a highly secretive programme for the kidnap, secret detention, and torture of terror suspects. The CIA's Rendition, Detention and Interrogation (RDI) programme saw the CIA build and run a global network of secret prisons wherein at least 119 prisoners were held for months and year on end, incommunicado, and with no access to legal representation. The excruciating details of the torture and abuse of prisoners has emerged over many years, and was confirmed at length in December 2014, when the US Senate Select Committee on Intelligence published the heavily redacted 499-page Executive Summary of its investigation into CIA torture (SSCI 2014) (hereafter SSCI report). The torture included drowning to the point of unconsciousness, repeated beatings, the use of ice baths and hoses to induce hypothermia, sleep deprivation for more than a week at a time, painful stress positions for months at a time, prolonged confinement in extremely small boxes, and sexual assault by forced feeding through the rectum (SSCI 2014: 3-4). Prisoners were threatened with power drills and subjected to mock executions, and were often beaten so severely that they passed out. Those detained in the CIA programme were subjected to a regime designed, as one interrogator stated, to take them 'to the verge of death and back again' (ICRC 2007: 17).

In January 2011, we were awarded a UK Economic and Social Research Council grant to map and analyse the contours of the CIA's RDI programme. ${ }^{1}$ As we describe in detail elsewhere (Raphael et al. 2015), identifying the aircraft that were secretly contracted by the CIA for the transfer of prisoners between its secret network of prison sites, and tracking the movements of those aircraft through the collection of related air traffic control data, has been central to our efforts to map the evolution of the RDI programme. Well before the publication of the SSCI report in 2014, through our collaborative work with the UK legal action charity Reprieve, we were able to identify the locations of a number of the secret prison sites the CIA had built, or those sites where prisoners were being held by third party states on behalf of the CIA. We were able to match specific prisoners to specific rendition operations by specific aircraft. Our work involved the collection, collation, and analysis of over 11,000 flight records, pertaining to all flights by aircraft known or suspected of involvement in the RDI programme between 2001 and 2010, culminating in our development of the Rendition Flights Database (Raphael and Blakeley 2013) (hereafter, Database). With the publication of the SSCI report, many of our findings were corroborated, while we have also been able to match further prisoners to specific rendition operations. Our investigation is ongoing, and has developed a number of investigative research methods which continue to reveal the dynamics of the RDI programme. Some of these new findings are described below.

In her article, 'Measuring extraordinary rendition and international cooperation', published in International Area Studies Review, Rebecca Cordell seeks to subject the Rendition Flights Database to a model-based statistical analysis. She argues that her analysis suggests that more countries were involved in the CIA's rendition programme than our work has previously established, and that many more flights in the Database than we have identified are likely to be connected to rendition operations. While we would not dispute the likelihood that both of these statements are correct, and we have always presented our findings with an acknowledgement that they provide a necessarily limited account of the RDI programme, we suggest that Cordell's work should be approached with some caution. This is so for two reasons. First, her findings - although derived through a different mode of analysis from our

\footnotetext{
${ }^{1}$ Economic and Social Research Council: The Globalisation of Rendition and Secret Detention, RES000-22-4417
} 
own - do not appear to move beyond those we have already published. Although it has been difficult to verify the exact overlap, given that Cordell has not published her full findings, we have for several years published details of nearly 500 flights in the Database which involved a landing at an airport close to a known secret detention location, or known prisoner pick-up location. ${ }^{2}$ These flights are part of circuits which involve more than 80 separate countries. Cordell's 307 'new likely rendition flights' (p. 5), appear in the Database, as do the 15 'previously unidentified participating countries'. As such, Cordell's analysis, as far as we are able to ascertain, replicates our existing findings. This is, of course, welcome. Second, as we explain below, because Cordell has not triangulated her analysis with either data relating to transfers of specific prisoners, or with evidence relating to which countries hosted prisons for the $\mathrm{CIA}$, and the operational dates for these prisons, we question her claim that the flights she has identified from the Database are 'likely rendition flights'.

In this article, we aim to demonstrate the importance of having a clear understanding of the limitations of big data when researching violations of human rights, especially where such data is related to covert operations. We also seek to show why the Renditions Flights Database only has merit when it is triangulated with a wide range of supplementary sources, including first-hand accounts by prisoners themselves, declassified documents from the US Government, and the findings of parliamentary, journalist and legal investigations. It is this process of triangulation which gives the flight data meaning and which makes it of value for establishing the facts of prisoner detention, rendition and torture.

\section{The Rendition Flights Database Methodology}

We begin by offering a brief account of the methodology we used to collate and analyse the air traffic control data relating to aircraft involved in rendition operations. Each aircraft in the Database has been included because it has been the focus of one or more past investigations into CIA rendition. However, this does not mean that all of these aircraft were actually involved in the RDI programme, and indeed it is highly likely that a number were not. Even where aircraft have been demonstrated to have some connection with the programme, or there are otherwise grounds to suspect their involvement, it does not follow that all flights by that aircraft in the Database are linked to rendition and secret detention. Indeed, many of the aircraft associated with rendition are privately owned, and performed business for the CIA alongside a range of other clients (both US Government and private.) Many of the flights in the Database therefore have nothing to do with rendition, and will not even have any connection with the US Government.

In determining which flights in the Database were, or might have been, rendition operations, we initially ordered all of the data by aircraft tail number and date, and determined whether particular patterns of journeys were indicative of a rendition operation having taken place. ${ }^{3}$ Many rendition circuits have a similar 'fingerprint'. Aircraft would fly from their home base, usually on or near the east coast of the US, to Washington Dulles International Airport. There they would stop for around an hour while the rendition team were brought on board. Then they would fly towards the pick-up airport, often stopping en route to refuel, and occasionally stopping overnight. The rendition flight itself, however, was usually focused and direct. The aircraft would stop at the pick-up and drop-off airports for a short time - often under an hour unless it was on a US-controlled airbase (such as in Afghanistan). It would generally be at night, and the transfer would be a direct flight where possible, stopping only for refuelling where absolutely necessary (such as the renditions from Southeast Asia to North Africa which stopped on the British Indian Ocean Territory of Diego Garcia). Circuits rarely involved one aircraft shuttling between airports, picking up detainees on the way (although the September

\footnotetext{
${ }^{2}$ https://www.therenditionproject.org.uk/flights/flight-database.html

3 We provide a detailed account of our methodology here:

http://www.therenditionproject.org.uk/flights/methodology.html
} 
2003 rendition of numerous 'High-Value Detainees' between prisons is an exception to this). Detainees were never taken out of the aircraft while stopped en route, and only left on the aircraft for extended periods of time where events did not go to plan (such as the June 2004 aborted rendition of Laid Saidi from Afghanistan to Tunisia). ${ }^{4}$ After all renditions had been completed, the aircraft would then often stop overnight at one or other of the 'rest and relaxation' points, such as the Azores or the Turks and Caicos islands. They would then generally return to Washington, and then to their home base.

Identifying the existence of such 'fingerprints' in the data was only a first step, however. To determine whether these circuits constituted rendition operations, the circuit data was triangulated with corroborating evidence beyond the Database, including: whether there was evidence of prisoners being transferred on or around those dates; whether the use of specific airports were indicative of a rendition operation (for example, if they were located near to known or suspected prisons); and documentary evidence confirming the rendition operation, for example, documentation relating to the contracting of specific aircraft by the CIA. This external data was crucial to our work over several years to fully interrogate every record in the Database and determine which records likely pertained to rendition operations, and which did not. Over a number of years, we have systematically triangulated the flight data with huge amount of prisoner and black site information buried in the pages of the SSCl report, hundreds of declassified documents, testimonies from victims of rendition programmes, and investigative work by human rights investigators and litigators. We describe this work in detail in our article, 'Tracking rendition aircraft as a way to understand CIA secret detention and torture in Europe' (Raphael et al. 2015).

\section{Welcome replication of our findings}

Cordell claims that her results suggest an additional 307 rendition flights that are identical in every way to known renditions, and that involve 15 previously unidentified countries (p.3). As noted above, we have already published details of nearly 500 flights landing at locations known to be near to secret detention facilities used in the War on Terror. To date, we have been able to tie approximately one-third of these flights to the transfer of specific prisoners, leaving over 320 flights flagged as 'suspicious'. Cordell has not published her full findings, so we have not been able to cross-match her 307 flights with both known and suspicious flights in the 500 flights that have been made publicly available for several years. We presume, however that the 307 are within our group of approximately 500 known or suspicious flights. As one example, the September 2005 circuit flown by known rendition aircraft N248AB, discussed by Cordell as indicative of her new findings (p. 7), has already been publicly tagged by us as a suspicious circuit (displaying some the core characteristics of a renditions operation.)

A similar story can be told with regards to the countries identified as providing a supportive role to the RDI programme through the use of their airports for refuelling. Cordell claims that only 54 countries have been identified as playing this role. This is incorrect: we have identified 65 countries involved in known rendition operations, and an additional 17 countries involved in circuits we have tagged as suspicious (see below). Indeed, of Cordell's 15 'previously unidentified countries', five (Japan, Malta, Norway, Seychelles and Tunisia) are already known to have been involved in specific rendition operations, where we have identified the prisoners rendered on board. For example, the rendition aircraft N63MU stopped over in Japan in December 2002, just before rendering Abu Zubaydah and Abd al-Rahim al-Nashiri from Thailand to Poland. A further seven countries (Brazil, France, Dominican Republic, Jamaica, Kuwait, Qatar, Senegal) exist in our public Database as connected to suspicious circuits. Cordell's work, therefore, does seem to replicate a number of our findings. There is insufficient

\footnotetext{
${ }^{4}$ https://www.therenditionproject.org.uk/prisoners/saidi.html
} 
evidence, however, that new rendition operations involving specific prisoners arise from her findings.

\section{Limitations of statistical modelling}

We welcome the fact that the modelling Cordell has used appears to replicate our findings. We also acknowledge that this kind of modelling can be extremely valuable in seeking to quantify the scope of a human rights issue (Root 2016: 355). Indeed, such analyses can provide distinct benefits, helping to 'demonstrate the scope, distribution (over geography and/or time), or variance of a human rights problem' (Root 2016: 356). There are, however, also dangers inherent in deploying such techniques in isolation. With Root, we share the view that in adopting quantitative methods, we need to exercise caution, not least because 'numbers do not, and cannot, equal "the truth"' (Root 2016: 357). Indeed, a particular challenge lies in understanding 'what can be said with data or statistical findings in regards to description, inference, and attribution of association or causality' (Root 2016: 356-7).

There are several important reasons why we have not claimed that the 320 'suspicious' flights are likely to be rendition flights. First, many of these flights do not connect prison pick-up locations with secret prison locations, nor do they connect two separate secret prison locations. This makes such flights highly unlikely to be rendition flights. For example, contained in our 320 flights (and therefore almost certainly in Cordell's 307 flights) are flights from the United States to Iraq and back, with a stopover in Europe each way for refuelling. It is unclear which leg in this circuit Cordell believes is the rendition, given that there is no evidence of renditions from the US to Iraq or vice versa.

Second, even where flights do connect two secret prison locations, when these take place outside of the dates when those prisons were operational they are clearly not rendition operations. Again as an example, the September 2005 'new rendition flight' between Guantánamo Bay and Afghanistan (via Shannon) (p. 7) is clearly not a rendition operation, given that the two CIA prisons at Guantánamo were closed by April 2004 in anticipation of the US Supreme Court ruling in Rasul et al V. Bush, President of the United States, et al (US 2004).

Third, without triangulating these flights with known dates when prisoners were moved between secret prisons, Cordell's findings are little more than speculation. To arrive at her findings, Cordell subjects the Database to analysis based on a model comprising four criteria:

1) Flight lands within close proximity to a confirmed CIA secret detention site

2) Flight also lands at a well-known staging post during the circuit

3) Aircraft has been previously used during past renditions of detainees

4) Flight also lands at Washington Dulles International Airport during the circuit

There are problems with using the above criteria, particularly out of context and in isolation from corroborating evidence outside of the Database. Regarding 1) as outlined above, aircraft will have been used for all sorts of purposes, by a range of corporate actors, and also US government departments. To illustrate this point, we know that a CIA prison operated near Kabul. Some of the circuits we identified as rendition circuits do involve stop offs in Kabul. However, there are numerous stops in Kabul that can't be connected to rendition operations through triangulation with other data. Just because an aircraft stopped there does not mean it was part of a rendition operation. During the early years of US-led operations in Afghanistan, there would have been many US government and private contractors flying into Kabul and needing to do so using private jets because there were no or few other options for flying into Afghanistan. Commercial airlines ceased or severely limited their flights in and out, as often happens in conflict. Therefore, just because there are stop offs of flights in the Database in or near Kabul does not mean such stops were rendition operations. In relation to 2), the same 
problems arise as with 1), i.e. numerous European airports were used for refuelling by these small private jets, during the course of activities by corporations that will have contracted those aircraft for activities that had nothing to do with rendition. In relation to 3), just because an aircraft has been used for rendition in the past does not mean every journey taken constitutes a rendition operation, as explained above. Finally, in relation to 4), Washington Dulles is a major international transfer hub. These aircraft would have regularly transited through Dulles airport in the conduct of all kinds of business, whether for private corporations, for contracts by the US government, or for CIA operations. Cordell's model seems to be built on the assumption that if an aircraft took a route involving a stop in Dulles, a stop at a refuelling point that had previously been used for refuelling during rendition operations, and if it stops in a location near to where a CIA prison operated, it must therefore be evidence of a rendition operation.

While we would agree that these four criteria do largely (although by no means always) characterise rendition operations, we would strongly dispute that they are sufficient to establish the existence of rendition operations. To draw this conclusion, as Cordell does, is an over-reach in interpreting the data. These flights could just as easily be flights taken by private security firms, private companies, aid agencies, UN officials, all with perfectly legitimate reasons for flying to the various locations in question. What is needed is a direct connection between two black sites, or between known pick-up points and one black site. Conversely, the gaps in the dataset mean that an absence of landings at Washington is no indication that the circuit was not a rendition operation.

\section{Why triangulation matters}

As well as making a scholarly contribution, our work has been motivated by the aim of ensuring the work can feed into litigation and accountability processes. To achieve this, meticulous triangulation of the flight data with a range of other sources, and in particular, the SSCI report, has been critical. Our analysis of the $\mathrm{SSCl}$ report provides a large amount of evidence, including which prison sites operated where and when, and which prisoners were held in each location. We can illustrate the very fine-grained analysis that underpins our findings with reference to specific details that were redacted from the SSCI report. These redactions included key details such as locations of prison sites, and throughout the report each of the CIA black sites is referred to by a pseudonym, such as BLUE, GREEN, COBALT. Information which could identify the countries in which those prisons was located is also redacted. However, our analysis of the flight data, alongside a range of supplementary sources of evidence, including other US declassified documents, has meant that we have been able to identify each of the prison sites and, as such, un-redact the locations of the prisons in the $\mathrm{SSCl}$ report.

For example, it has been possible to name a number of the prisoners that were held together in Poland between 2002 and 2003, and tie accounts of their individual abuse to their time in that country. It can, in turn, be established with a very high degree of certainty that the first rendition flight into Poland, from Bangkok to Szymany in December 2002, had Abu Zubaydah and Abd al-Rahim al-Nashiri on board. The SSCI report states that 'in December 2002, when DETENTION SITE GREEN was closed, al-Nashiri and Abu Zubaydah were rendered to DETENTION SITE BLUE.' (SSCI 2014: 67). Triangulating these with two further US Government documents, each of which has been partially declassified (but with differing information left un-redacted in each case) reveals the exact day of the transfer (4 December 2002) and the fact that the two men were transferred together from one location to another (DoJ 2009: 85; OIG 2004, para 76). Flight data documents only one possible transfer by a rendition aircraft between known sites on that day, namely the trip by N63MU from Thailand to Poland. Matching flight data with the SSCI report in other cases confirms that DETENTION SITE BLUE was in fact the Polish site. For example, the SSCI report states that 'officers at $\mathrm{CIA}$ Headquarters decided that the CIA should obtain [redacted] custody of [Ramzi] bin al- 
Shibh [from the custody of a foreign government] and render him to DETENTION SITE BLUE in Country [redacted].' The report then provides indications of when this rendition took place: 'on February [redacted], 2003, in anticipation of bin al-Shibh's arrival, interrogators... prepared an interrogation plan.' (SSCI 2014: 76). Unattributed comments by CIA officials have suggested that the foreign government concerned was Morocco, a fact which is supported by flight data matching the SSCI report's earlier assertion that he was captured in Pakistan on 11 September 2002 and rendered to a foreign government 'on September [redacted], 2002.' (Goldman 2007; SSCI 2014: 75). ${ }^{5}$ By 12 February 2003, 'CIA interrogators at DETENTION SITE BLUE assessed that bin al-Shibh was cooperative.' (SSCI 2014: 78). Bin al-Shibh's rendition from the custody of a foreign government (Morocco) to DETENTION SITE BLUE therefore took place at some point 1-12 February 2003. Flight data provides independent confirmation of this rendition, and reveals the location of DETENTION SITE BLUE: the Gulfstream V with registration N379P flew from Morocco to Poland on 6 February 2003. ${ }^{6}$

Matching the flight data to references to prisoner transfers throughout the $\mathrm{SSCl}$ report has been central to our ability to establish the locations and dates of operation of all of the secret CIA prison sites, as follows: GREEN (Thailand, March 2002 to December 2002); COBALT (Afghanistan, September 2002 to April 2004); GREY (Afghanistan, 2003, exact dates unknown); ORANGE (Afghanistan, April 2004 to September 2006); BROWN (Afghanistan, March 2006 to 2008); MAROON and INDIGO (Guantánamo Bay, September 2003 to April 2004); BLUE (Poland, December 2002 to September 2003); BLACK (Romania, September 2003 to November 2005); and VIOLET (Lithuania, February 2005 to March 2006). Through our reading and analysis of numerous declassified documents, especially the SSCI report, we can also provide a clear explanation for the opening and closing of the various prison sites.

In the initial weeks of the RDI programme, the CIA considered various options for covert prison sites. In the end the CIA decided that US Department of Defense facilities were the 'best option', but urged the US military to agree to hosting a long-term CIA facility at the US naval base in Afghanistan (SSCI 2014: 12). Nevertheless, the CIA continued with its plans to identify partner states that could host purpose built CIA sites, the first of which was Thailand. Operational from March 2002, both Abu Zubaydah and Abd al-Rahim al-Nashiri were held there. Abu Zubaydah was transferred there from Pakistan on 31 March 2002, and al-Nashiri was transferred there on 15 November 2002. This was also where the CIA first deployed the so-called 'Enhanced Interrogation Techniques' (EITs), including waterboarding, against both of these prisoners (SSCI 2014: 40-49; 67). By November 2002, however, there had been too many leaks about the site, and the CIA knew that a major US newspaper had learned that Abu Zubaydah was being detained in Thailand. Fearing exposure, it persuaded the newspaper not to publish the story, but also took the decision to close the site down (SSCI 2014: 24), and then in early December 2002, the CIA moved both prisoners to the newly established CIA prison site, BLUE, in Poland. ${ }^{7}$ The SSCI report indicates that BLUE was originally intended for just two detainees (SSCI 2014: 62), but within 6 months, it was holding 5 people which was beyond the capacity of its 'three purpose built "holding units"' (SSCI 2014: 62). Meanwhile, in Afghanistan, the CIA was detaining more and more prisoners at its COBALT site, referred to be detainees as the 'Dark Prison' because they were kept in 'complete darkness and isolation' (SSCI 2014: 62). COBALT had 20 cells, and held at least 64 prisoners, although as the SSCI report makes clear, CIA record keeping was poor (SSCI 2014: 67, footnote 338)), so the actual number may be higher. As with GREEN, COBALT was also a site where the CIA extended its use of the EITs.

\footnotetext{
${ }^{5}$ For the matching flight data, see: https://www.therenditionproject.org.uk/flights/renditions/N379P020911.html

${ }^{6}$ For the matching flight data, see: https://www.therenditionproject.org.uk/flights/renditions/N379P030206.html

${ }^{7}$ For the matching flight data, see: https://www.therenditionproject.org.uk/flights/renditions/N63MU021203.html
} 
By mid-August 2003, as Black and Raphael have shown (Black and Raphael 2015), the programme was well over-capacity. In September 2003, the Polish site BLUE was closed, and some of its prisoners were sent on to the new BLACK site in Romania, while the rest were transferred to two CIA sites in Guantánamo Bay, MAROON and INDIGO. They temporary site in Morocco was also closed and the two prisoners being held there, bin al-Shibh and alNashiri, were moved on to Guantánamo Bay. The new Guantánamo sites did not last long. In anticipation of the US Supreme Court ruling in Rasul et al V. Bush, President of the United States, et al, in which it was expected that the prisoners held at Guantánamo would be granted certain rights, including habeas corpus (US 2004), the CIA moved to transfer the prisoners out and did so on a series of flights to Morocco and Romania between 27 March and 14 April 2004. ${ }^{8}$ One US official confirmed that the CIA prison in Guantánamo was closed down because the US feared its CIA programme would be exposed (Black and Raphael 2015). The programme was now at its peak, with some 50 or 60 prisoners being held at various locations. The CIA also discovered it was holding people it new very little about (SSCI 2014: 110). Around the same time, the International Committee of the Red Cross informed US authorities that it was aware of the incommunicado detention of prisoners in Afghanistan for extended periods, and of considerable mistreatment. It had also compiled a fairly accurate list of prisoners. As a result, the CIA decided it must reduce the number of prisoners (SSCI 2014: 119). As Black and Raphael have shown, around May 2004, 18 prisoners were transferred to US military custody in Bagram, five were released, and seven were transferred to foreign custody. COBALT was closed down and a new facility, ORANGE, replaced it in Afghanistan, with prisoners transferred there en masse. (Black and Raphael 2015). In late June 2004, 34 prisoners were located across the remaining sites in Afghanistan, Romania, and the reestablished temporary site in Morocco. By December that year, 29 remained. While numbers were tapering off, other problems arose, and the CIA still had to find additional accommodation. Moroccan officials had lost patience with the CIA which they accused of being unappreciative, so in February 2005, those prisoners were transferred to the new VIOLET facility in Lithuania (Black and Raphael 2015). ${ }^{9}$ Just four new prisoners entered the programme in 2005. In March 2006, Lithuania was closed, in part because of media leaks which threatened to expose further details of the programme (SSCI 2014: 153). Those being held in Lithuania were transferred to a new site, BROWN in Afghanistan. By this point, the CIA and DoD were in dispute, with the CIA looking to wind the programme down, but Secretary of Defense Rumsfeld was refusing to receive any more CIA prisoners into US Department of Defense custody (SSCI 2014: 156). The CIA therefore began sending some prisoners on to custody in third party states, including Pakistan, Libya, Jordan and Yemen (Black and Raphael 2015). The remaining high value detainees, fourteen in total, were finally transferred to US military custody in Guantánamo in early September 2006, when President Bush admitted publicly that the RDI programme had operated.

As the indicative account above makes clear, this type of analysis - at the heart of which requires a triangulation of flight data with supplementary sources - underpins not just our accounts of those flight circuits we have identified as rendition operations, but also our account of the overall contours of the RDI programme. It is only by understanding this broader picture that we can adequately identify specific rendition operations and, conversely, it is the consideration of how such operations overlap with other elements of the programme which enable a richer picture of CIA torture to be drawn.

\footnotetext{
${ }^{8}$ For the matching flight data, see: https://www.therenditionproject.org.uk/flights/renditions/N85VM040326.html and https://www.therenditionproject.org.uk/flights/renditions/N85VM-040411.html

${ }^{9}$ For the matching flight data, see: https://www.therenditionproject.org.uk/flights/renditions/N724CL050216.html and https://www.therenditionproject.org.uk/flights/renditions/N787WH-050214.html
} 


\section{Conclusion}

Researching the covert and illegal practices of state security agencies is fraught with challenges, precisely because of the secretive nature of state violence. In attempting to determine the scope of a particular human rights problem, there are very good reasons for exploring new methods that might help uncover the most egregious human rights abuses. Our work to map and analyse the flight data relating to aircraft contracted by the CIA for use in rendition operations provides one example of the potential of big data in human rights factfinding. In this paper we have attempted to show that the flight data was only made meaningful through its triangulation with a wide range of additional evidence. Perhaps most important of these were the accounts of the victims themselves. Also significant were the declassified, if heavily redacted, documents from various arms of the US government which provided partial accounts of aspects of the RDI programme.

We hope to have demonstrated that Cordell's work to subject the Rendition Flights Database to analysis using statistical modelling techniques has been valuable in so far as it appears to have replicated our findings. However, the claim that it has resulted in the identification of further likely rendition operations is not supported by the evidence. To substantiate this claim, the flight data would need to be triangulated with a range of other sources, described above, which could connect those flights to prisons that were operational at the time that the flights took place, and then, to the prisoners that were held within them. Critical to such efforts are the testimonies provided by prisoners, accounting for their own journeys through the RDI programme, but also providing information about other prisoners they were held with, in the various prison sites. Also critical are the originally classified CIA records, memos and cables which have been partially uncovered by the SSCI report. These have helped us to corroborate our findings derived through analysis of the flight data. We have therefore demonstrated that big infrastructural data can only ever be supplemental to victim testimonies in establishing the facts of human rights violations, and where available, to official records, particularly if the knowledge produced is to be of use in holding states to account, or seeking redress for victims. 


\section{Bibliography}

Black, Crofton and Raphael, Sam (2015), 'Revealed: The Boom and Bust of the CIA's Secret Torture Sites', The Bureau of Investigative Journalism, (14 October).

$<$ https://www.thebureauinvestigates.com/2015/10/14/revealed-cia-torture-black-siteshistory-boom-bust/>.

Goldman, Adam (2007), 'Secret Jails: Terror Suspect's Odyssey through CIA's 'Black Sites". $<$ http://hosted.ap.org/specials/interactives/wdc/binalshibh/content.swf>.

Internatioanl Committee of the Red Cross (ICRC) (2007), 'ICRC Report on the Treatment of Fourteen "High Value Detainees" in CIA Custody', February.

<http://www.therenditionproject.org.uk/pdf/PDF\%20101\%20[ICRC,\%20Feb\%202007. \%20Report\%20on\%20Treatment\%20of\%2014\%20HVD\%20in\%20CIA\%20Custody]. pdf>.

Raphael, Sam and Blakeley, Ruth (2013), 'Rendition Flights Database', (22 May). $<$ http://www.therenditionproject.org.uk/flights/index.html>.

Raphael, Sam, et al. (2015), 'Tracking rendition aircraft as a way to understand CIA secret detention and torture in Europe', The International Journal of Human Rights, 20 (1), 78-103.

Root, Brian (2016), 'Numbers are Only Human. Lessons for Human Rights Practitioners from the Quantitative Literacy Movement', in Philip Alston and Sarah Knuckey (eds.), The Transformation of Human Rights Fact-Finding (Oxford: Oxford University Press), 355-76.

US Department of Justice (DoJ) (2009), 'Report: Investigation into the Office of Legal Counsel's Memoranda Concerning Issues Relating to the Central Intelligence Agency's Use of "Enhanced Interrogation Techniques" on Suspected Terrorists', Office of Professional Responsbility, Department of Justice, 29 July. $<$ www.therenditionproject.org.uk/documents/RDI/090729-DoJInvestigation CIA EITs.pdf>.

US Office of the Inspectpr General (OIG) (2004), 'Special Review: Counterterrorism Detention and Interrogation Activities (September 2001-October 2003)', (7 May). $<$ http://www.therenditionproject.org.uk/pdf/PDF\%2020\%20[CIA\%20IG\%20Investigati on\%20EITs\%202004].pdf>

US Senate Select Committe on Intelligence (SSCI) (2014), Committee Study of the Central Intelligence Agency's Detention and Interrogation Program, declassified Executive Summary', (3 December).

<https://www.therenditionproject.org.uk/documents/RDI/141209-SSCI-

Torture_Report_Executive_Summary.pdf>

US Supreme Court (2004), 'RASUL et al. v. BUSH, PRESIDENT OF THE UNITED STATES, et al.', 28 June. <https://www.law.cornell.edu/supct/html/03-334.ZS.html>. 